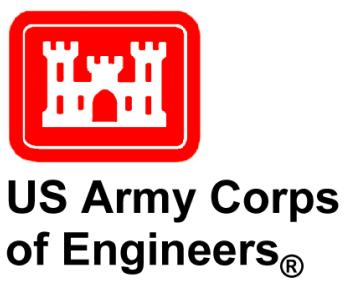

\title{
Exudate Chemical Profiles Derived from Lespedeza and Other Tallgrass Prairie Plant Species
}

by David B. Ringelberg, Alyssa M. Beck, Ryan R. Busby, Imee G. Smith, and Anthony C. Yannarell

ABSTRACT: Lespedeza cuneata is an introduced legume that is invasive in the tallgrass prairie system and open woodlands of North America. This system includes native Lespedeza species that coexist with $L$. cuneata, including $L$. capitata and L. virginica. Previous research has indicated that $L$. cuneata exudates have profound influences on soil biological functions. The goal of this current research was to identify and then compare exudate chemicals from L. cuneata, L. capitata, L. virginica, and common tallgrass prairie grasses. Exudates from Lespedeza species were found to be distinct from the grasses. In particular, L. cuneata and, to a lesser extent, a subset of $L$. virginica could be differentiated based on the presence of five unique compounds. Two low molecular weight compounds were identified via gas chromatography/mass spectrometry (GC/MS) and tentatively identified as benzophenone and 1,4-diacetylbenzene. Three higher molecular weight compounds were identified by liquid chromatography-electrospray ionizationmass spectrometry (LC-ESI-MS), with possible relationships to a $3 ß$ sterol, phosphatidylglycerol, and the 19-nor analogues of vitamin D. The relative abundance of these compounds were found to be greater in the invasive species, L. cuneata, than in the native noninvasive species, L. virginica. These results are an integral step in further understanding through chemical exudation how $L$. cuneata can be benefiting from greater rhizobial associations.

PURPOSE: To address the concept of whether L. cuneata successfully alters the native soil microenvironment through the action of specific exudates.

INTRODUCTION AND BACKGROUND: Military training often creates unique disturbances that affect biological communities in the lands where training occurs, such as the introduction and establishment of invasive species. Invasive species often become established by outcompeting native organisms for resources with their subsequent growth and metabolism leading to an alteration of ecosystem processes. Over $\$ 100$ billion is spent annually to clean up and contain invasive species (Pimental et al. 2005). This high cost is largely the result of a knowledge gap regarding how foreign species so easily establish footholds and maintain dominance in certain specific geographical areas. To better understand how invasive species become established and dominant in an environment, this work examines the interrelationships that exist between (a) plant-associated microbiota from closely related native and (b) introduced congeneric plant species. The hypothesis being tested is that if Lespedeza cuneata successfully alters the native soil microenvironment through the action of specific exudates, then this alteration will impart a competitive advantage to the plant either through enhanced nutrient uptake or decreased competition.

The introduced leguminous plant Sericea lespedeza (Lespedeza cuneata) is an aggressive invader of military training and testing areas across the eastern United States, with a documented occurrence at 11 Tier 1 Army installations (Denight and Busby 2007). This plant appears to benefit from 
the physical disturbances caused by military testing and training, and it subsequently impacts training by forming dense monocultures that are difficult to traverse, obscuring hazards through its thick growth, and reducing stem densities resulting in increased erosion.

Lespedeza cuneata's current range in North America overlaps with native Lespedeza species, including the widespread L. virginica and L. capitata (Busby et al. 2016). L. cuneata forms extensive stands (Yannarell et al. 2011) and benefits from greater rhizobial associations than does L. virginica (Hu et al. 2014). Further, nodule-associating bacteria differ significantly in taxonomy between $L$. cuneata and L. virginica when coexisting in a single stand (Busby et al. 2016). Previous research has demonstrated that individual chemical exudates, in particular the phenolic compounds, can have a significant influence on the soil microbial community (e.g., by selecting for different bacteria, by stimulating and/or suppressing bacterial growth, and by altering species richness and composition) (Badri et al. 2013). L. cuneata has a high polyphenol content, and L. cuneata root exudates have been previously shown to have inhibitory effects on perennial grasses (Kalburtji and Mosjidis 1993). These previous findings suggest that a variation in root exudate production between the invasive and native Lespedeza species may impart a competitive advantage to the invasive species as secondary metabolites, when exuded into the soil, by affecting the plant rhizobial association.

This report begins to address the concept of whether $L$. cuneata successfully alters the native soil microenvironment through the action of specific exudates. Following cultivation in soil and subsequent acclimation in hydroponic culture medium, exudates from L. cuneata and related species were collected in a sterile salt solution and assayed by liquid chromatography-tandem mass spectrometry (LC-MS/MS) and gas chromatography/mass spectrometry (GC/MS). The objective was to elucidate exudate profiles from the invasive and noninvasive species for comparison and potential identification of unique, L. cuneata-specific compounds. The native species selected for comparison included members of the same genus (i.e., L. virginica and L. capitata) as well as common tallgrass prairie grass species currently found in association with Lespedeza (Panicum virgatum, Andropogon gerardii, and Schizachyrium scoparium).

MATERIALS and METHODS: Plants (Lespedeza cuneata, L. virginica, L. capitata, P. virgatum, $A$. gerardii, and $S$. scoparium) were individually grown in a 1:1 mixture of fine vermiculite (for moisture retention) and coarse quartz sand (for structure) with 1/4 strength Hoagland's nutrient solution [no. 2 basal salt mixture, Sigma-Aldrich] for 3 months (Phillips, Bernhardt, and Schlesinger). Ten replicate plants were grown per species. Plants were then transferred to hydroponic culture in $1 / 4$ strength Hoagland's nutrient solution for 1 week. This latter step was performed to allow the plants to acclimate to hydroponic culture prior to exudate collection. Following acclimation, root exudates were collected by transferring plants into pots containing $20 \mathrm{~mL}[1 \mathrm{mM}] \mathrm{CaSO}_{4}$ and incubating at room temperature for 3 hours. The $\mathrm{CaSO}_{4}$ solution was then filter sterilized [Millex-GV, $0.22 \mu \mathrm{m}$; millipore] and stored at $-20^{\circ} \mathrm{C}$ prior to analysis by LC-MS/MS and GC/MS.

LC-MS/MS analysis - A Waters Acquity ultra performance liquid chromatography (UPLC) system coupled with a Waters Synapt G2-Si mass spectrometer was used to analyze the $\mathrm{CaSO}_{4}$ extraction solutions. The LC-MS/MS system was equipped with a Waters ethylene bridged hybrid (BEH) C18 column $(100 \times 2.1 \mathrm{~mm}$ inside diameter, $1.7 \mu \mathrm{m})$. A mixture of methanol and water at a flow rate of $0.257 \mathrm{~mL} \mathrm{~min}^{-1}$ was used as the mobile phase with $1.4 \mu \mathrm{L}$ sample volumes injected. The eluent gradient started at $10 \%$ methanol, followed by a 25 min ramp to $90 \%$ methanol, and then quickly ramped back to the initial conditions followed by a stabilization period. The column temperature was kept at $30^{\circ} \mathrm{C}$. Chromatographically separated samples were analyzed in positive ion 
mode, and MS data were collected with time of flight (TOF) fast DDA (data dependent analysis) scans. The electrospray ionization (ESI) conditions were as follows: cone voltage, $40 \mathrm{~V}$; source temperature, $100^{\circ} \mathrm{C}$; capillary, $3.5 \mathrm{kV}$. The mass range for analysis was from 50 to $2000 \mathrm{~m} / \mathrm{z}$. MS/MS TOF survey data were collected following collision-induced dissociation at $2 \mathrm{eV}$ (no masses excluded).

Qualification of the exudate profiles was conducted by deriving the base peak intensity chromatograms (0.2 sec scan time). Base peaks and intensities were compiled for each sample analyzed, and the resulting profiles were expressed as relative peak intensities (\%), as compared by principal components analysis (based on correlations). The most distant replicate of each of the samples was removed prior to analysis (Euclidean distance; hierarchical cluster analysis; wards method). Related formula and structures were obtained by querying the METLIN (Scripps Research Institute) and MassBank (Institute for Bioinformatics Research and Development, Japan Science and Technology Agency) databases, respectively.

GC/MS analysis - Exudate solutions were analyzed on an Agilent 5977 Series gas chromatograph/mass selective detector (GC/MSD) system. Sample separation $(1 \mu 1)$ was carried out on an Agilent DB5-ms capillary column $(40 \mathrm{~mm} \times 250 \mu \mathrm{m} \times 0.25 \mu \mathrm{m})$ with a temperature gradient of $6^{\circ} \mathrm{C} / \mathrm{min}$ from $80^{\circ} \mathrm{C}(1 \mathrm{~min})$ to $110^{\circ} \mathrm{C}$, then $8^{\circ} \mathrm{C} / \mathrm{min}$ to $190^{\circ} \mathrm{C}$, and $15^{\circ} \mathrm{C} / \mathrm{min}$ to $270^{\circ} \mathrm{C}$, followed by a $2 \mathrm{~min}$ hold. The GC operating parameters were as follows: helium carrier gas flow, $1.2 \mathrm{ml} / \mathrm{min}$ flow rate; splitless injection at $250^{\circ} \mathrm{C}(53.2 \mathrm{ml} / \mathrm{min}$ flow $)$; and transfer line maintained at $280^{\circ} \mathrm{C}$. MSD parameters: source temperature, $250^{\circ} \mathrm{C}$; analyzer temperature, $150^{\circ} \mathrm{C} ; 3$ min solvent delay, and $\mathrm{eV}, 70$. The mass range for analysis was from 45 to $450 \mathrm{~m} / \mathrm{z}$. Total ion chromatograms were compared, and peaks were identified at a signal to noise threshold of 3:1 or greater.

RESULTS and DISCUSSION: The number of detectable compounds in the $\mathrm{CaSO}_{4}$ solution was low. Total ion LC-ESI-MS chromatograms revealed only a few peaks with a signal to noise ratio of 3:1 or greater (Table 1). Representative total ion LC-ESI-MS chromatograms for the invasive species $L$. cuneata and native species L. virginica are provided in Figure 1. Base peak chromatograms provided additional detail and, as such, were used to obtain a qualitative comparison across the six cultivated legume species. Results from a principal component analysis of base peak relative intensities ( $n=9$, per species) indicated differences among the plant exudate profiles (Figure 2). Analysis of principal component one loadings identified peaks with a base $\mathrm{m} / \mathrm{z}$ ratio of 701.5012, 453.3521, and 401.2732 as being heavily negative weighted in L. cuneata and L. virginica replicates (i.e., expressing a $>0.7$ correlation coefficient), which differentiated these two species from the other four. Replicates of $A$. gerardii exudates exhibited a positive correlation with principal component 2, with base peak m/z 457.2822 assigned a coefficient of +0.67 . However, of the six species analyzed, exudates from $A$. gerardii were characterized by the lowest relative abundance of detectable (via LC-ESI-MS) compounds (Table 1).

Exudate analysis by GC/MS also resulted in few detectable compounds (Table 2). Representative GC-MS chromatograms for the invasive species L. cuneata and native species L. virginica are provided in Figure 3. Similar to the LC-ESI-MS analysis, the GC-MS analyses indicated the presence of novel and more abundant compounds in the L. cuneata replicates as well as in four of the L. virginica replicates. Common to all of the $L$. cuneata replicates was a compound identified by GC-MS, described below, that eluted at a retention time of $15.39 \mathrm{~min}$. Compounds eluting at retention times of $12.32 \mathrm{~min}$ and $13.72 \mathrm{~min}$ were also found to be abundant in most, but not all, of 
the L. cuneata replicates analyzed. The compound eluting at $12.32 \mathrm{~min}$ was unique to the L. cuneata replicates, and the compound eluting at $13.72 \mathrm{~min}$ occurred in some of the native plant samples (e.g., L. virginica, P. virgatum and S. scoparium; see Table 2).

Results summary. All exudate profiles recovered from L. cuneata replicates contained a compound, detectable by LC-MS, with a base peak at $701 \mathrm{~m} / \mathrm{z}$. In addition, compounds exhibiting base peaks of 453 and $401 \mathrm{~m} / \mathrm{z}$ were detected in all but one of the nine L. cuneata replicates. Other than four replicates of $L$. virginica, these three compounds were not detected in any of the other plant species examined. A compound eluting at $15.39 \mathrm{~min}$, as detected via GC-MS, was also found to be unique to all nine of the L. cuneata replicates and to four of nine L. virginica replicates.

Figure 1. Representative base peak (black) and total ion (blue) LC-ESI-MS chromatograms of exudate profiles from $L$. cuneata (top) and $L$. virginica (bottom).

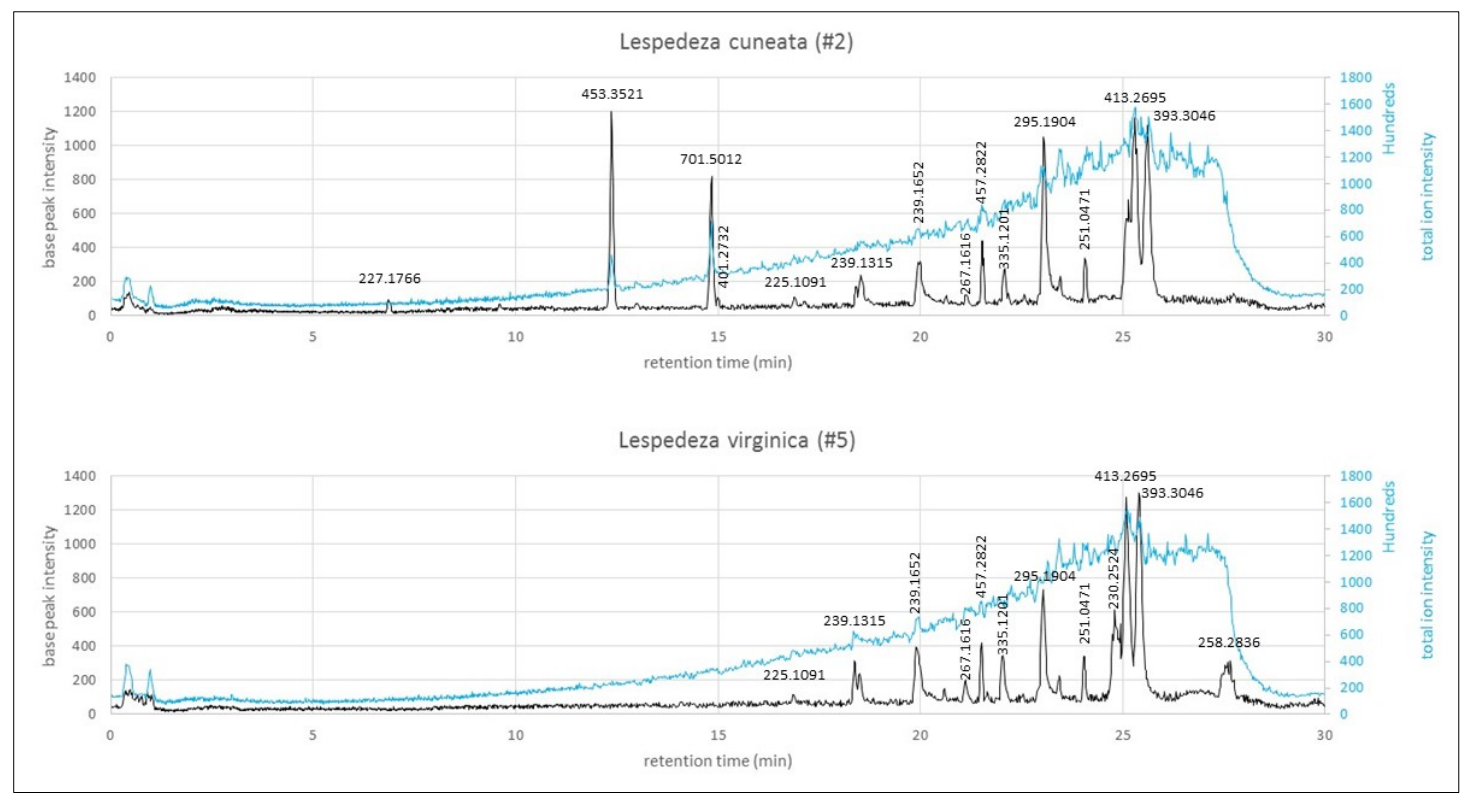


Figure 2. Results of a principal components analysis of exudate LC-ESI-MS base peak, peak heights, illustrating similarities and differences among leguminous plant exudate profiles.

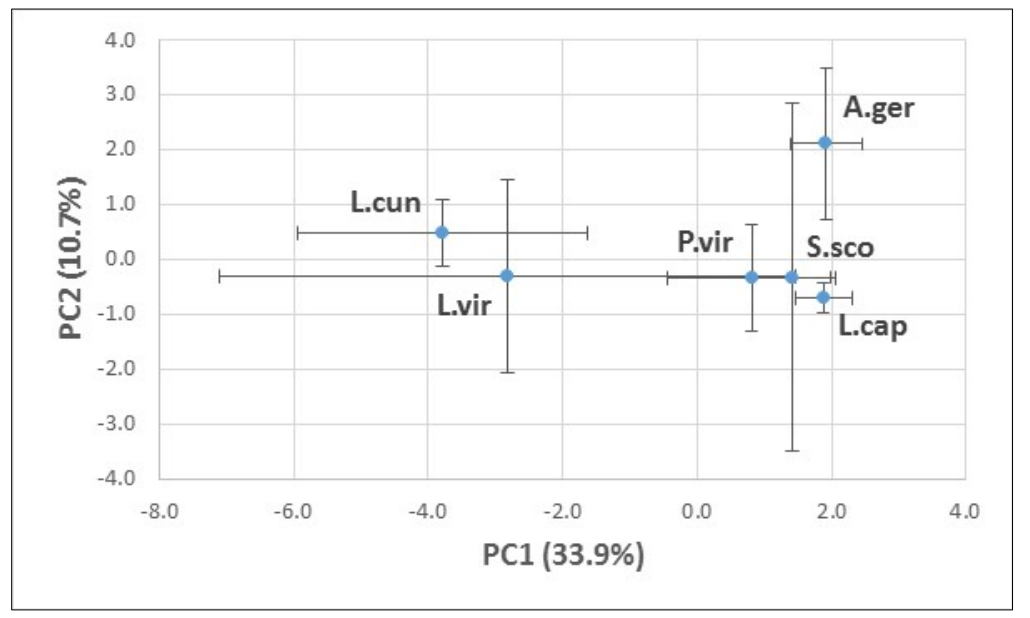

Table 1. Identified LC-ESI-MS base peaks in exudate profiles from six legumes. Peak retention times (rt), base peak $\mathrm{m} / \mathrm{z}(\mathrm{BP})$, and peak relative intensity $(\%)$ are provided.

\begin{tabular}{|l|r|r|r|r|r|r|r|}
\hline \multicolumn{7}{|l|}{ average relative peak intensity $(\%, \mathbf{n}=9)$} \\
\hline $\mathbf{r t}( \pm .04)$ & BP & L.cun & L.vir & P.vir & L.cap & S.sco & A.ger \\
\hline 6.85 & 227.1766 & 1.5 & 1.0 & 1.4 & 0.0 & 0.1 & 0.0 \\
\hline 9.60 & 245.1419 & 0.6 & 0.3 & 0.3 & 0.0 & 0.0 & 0.6 \\
\hline 12.37 & 453.3521 & 9.1 & 7.5 & 0.0 & 0.0 & 0.0 & 0.0 \\
\hline 14.83 & 701.5012 & 5.8 & 3.6 & 0.0 & 0.0 & 0.0 & 0.0 \\
\hline 14.97 & 401.2732 & 1.4 & 1.1 & 0.0 & 0.0 & 0.0 & 0.0 \\
\hline 16.89 & 225.1091 & 2.6 & 2.7 & 2.8 & 3.1 & 3.0 & 3.1 \\
\hline 17.19 & 163.0414 & 0.8 & 1.3 & 1.9 & 1.4 & 1.0 & 1.2 \\
\hline 18.39 & 376.2684 & 0.7 & 1.6 & 1.0 & 0.3 & 0.0 & 0.4 \\
\hline 18.52 & 239.1315 & 5.7 & 5.7 & 5.4 & 6.7 & 7.0 & 6.9 \\
\hline 18.76 & 237.1513 & 0.0 & 0.0 & 0.0 & 0.0 & 0.0 & 0.4 \\
\hline 19.98 & 239.1652 & 8.1 & 8.1 & 9.6 & 10.5 & 9.3 & 10.0 \\
\hline 21.15 & 267.1616 & 3.0 & 3.1 & 3.4 & 3.8 & 3.6 & 3.7 \\
\hline 21.56 & 457.2822 & 3.3 & 3.1 & 4.0 & 3.2 & 3.3 & 5.5 \\
\hline 21.75 & 365.1426 & 0.0 & 0.0 & 0.0 & 0.0 & 0.0 & 0.2 \\
\hline 22.01 & 301.1442 & 0.0 & 0.0 & 0.0 & 0.0 & 0.0 & 1.0 \\
\hline 22.10 & 335.1201 & 4.7 & 4.6 & 5.3 & 5.1 & 5.4 & 5.7 \\
\hline 22.18 & 163.0414 & 2.4 & 2.1 & 2.9 & 2.7 & 2.8 & 3.0 \\
\hline 23.07 & 295.1904 & 14.2 & 14.6 & 17.1 & 17.9 & 16.8 & 17.7 \\
\hline 24.10 & 251.0471 & 9.3 & 9.3 & 10.4 & 10.8 & 11.3 & 10.0 \\
\hline 24.38 & 122.0977 & 0.0 & 0.0 & 0.3 & 0.0 & 0.0 & 0.3 \\
\hline 24.91 & 230.2524 & 2.0 & 4.8 & 4.6 & 4.7 & 5.6 & 1.2 \\
\hline 25.20 & 413.2695 & 14.3 & 14.4 & 16.9 & 17.5 & 16.2 & 16.8 \\
\hline 25.39 & 393.3046 & 10.5 & 10.4 & 11.5 & 11.9 & 12.3 & 12.2 \\
\hline 27.55 & 258.2836 & 0.0 & 0.7 & 1.1 & 0.3 & 2.3 & 0.0 \\
\hline \hline & & & & & & & \\
\hline
\end{tabular}


Table 2. Identified GC-MS peaks in exudate profiles from six coexisting plant species. Peak retention times $(\mathrm{rt})$ and peak relative areas $(\%)$ are provided.

\begin{tabular}{|l|r|r|r|r|r|r|}
\hline \multicolumn{7}{|l|}{ ave rage relative peak area $(\%, \mathbf{n}=9)$} \\
\hline $\mathbf{r t}( \pm .04)$ & L.cun & L.vir & P.vir & L.cap & S.sco & A.ger \\
\hline 10.042 & 0.0 & 0.0 & 0.0 & 0.0 & 6.8 & 0.0 \\
\hline 12.316 & 5.3 & 0.0 & 0.0 & 0.0 & 0.0 & 0.0 \\
\hline 12.904 & 0.0 & 0.0 & 0.0 & 0.0 & 2.6 & 0.0 \\
\hline 13.724 & 5.6 & 2.1 & 36.2 & 0.0 & 8.0 & 0.0 \\
\hline 15.391 & 85.2 & 47.9 & 0.0 & 0.0 & 0.0 & 0.0 \\
\hline 15.932 & 0.0 & 1.6 & 2.9 & 7.2 & 0.0 & 0.0 \\
\hline 16.045 & 0.5 & 3.1 & 3.9 & 11.2 & 2.8 & 0.0 \\
\hline 16.568 & 0.3 & 0.0 & 3.5 & 3.4 & 0.0 & 0.0 \\
\hline 16.657 & 1.7 & 4.3 & 20.0 & 17.8 & 12.0 & 0.0 \\
\hline 16.714 & 1.4 & 3.5 & 11.3 & 15.9 & 12.2 & 0.0 \\
\hline
\end{tabular}

KEY: Lespedeza cuneata (L.cun); Lespedeza virginica (L.vir); Panicum virgatum (P.vir); Lespedeza capitata (L.cap); Schizachyrium scoparium (S.sco); Andropogon gerardii (A.ger)

Figure 3. Representative total ion GC-MS chromatograms of exudate profiles from $L$. cuneata (top) and $L$. virginica (bottom).

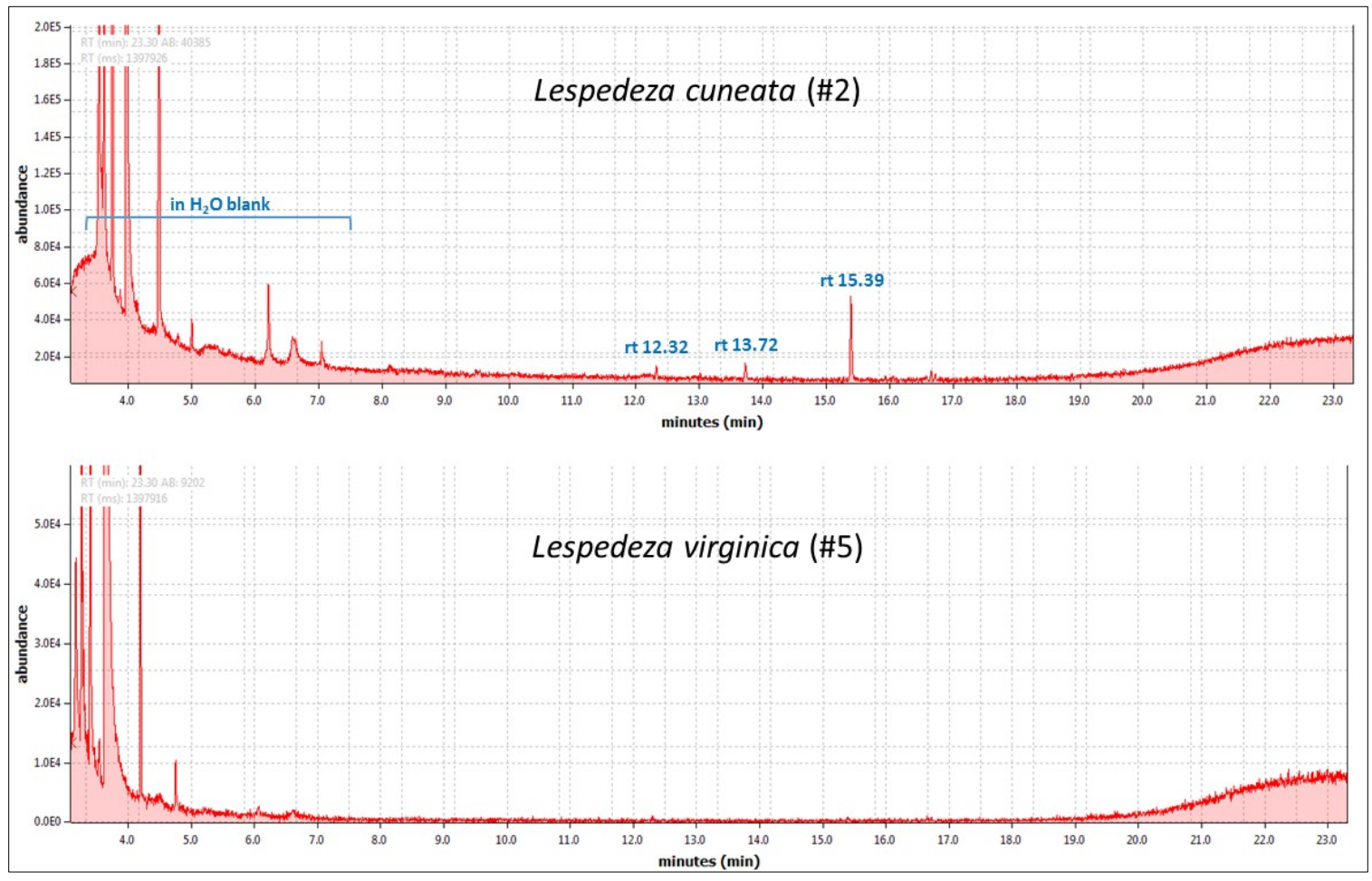

Preliminary identifications and potential formula for the five compounds of interest were examined. Mass spectral profiles are provided in Figure 4. The exact mass of each compound of interest, as determined by LC-ESI-MS, was derived from the fast DDA process of the Waters Synapt G2-S TOF MS. These masses were submitted to the METLIN and MassBank databases for query of possible compound identifications. No matches were obtained in comparison to the MassBank database. METLIN simple search results are summarized in Table 3. Results were consistent in the identification of a $5 \alpha$-chlostane-3ß-ol, phosphatidylglycerol and a 19-nor-vitamin 
(19-nor, vitamin D3). The 19-nor analogs of vitamin D (e.g., 1 alpha 25-dihydroxy-19-nor-vitamin D) show a selective activity profile with high potency in inducing cellular proliferation, differentiation, and calcium mobilization activity (Zhang et al. 2005). Increased calcium mobilization could affect plant defense signaling because the calcium ion is ubiquitous in its role as a secondary messenger involved in numerous plant signaling pathways. The ability to enhance cellular proliferation and differentiation could have in planta benefits and could affect surrounding plant development. Phosphatidylglycerol has been conserved in photosynthetic membranes from prokaryotes to eukaryotes. It plays a vital role as a cofactor of plant photosystems and has been implicated in plant tolerance to chilling (Wada and Murata 2007). The 5 $\alpha$-cholestane-3ß-ols, or bile alcohols, identified at a retention time of $12.37 \mathrm{~min}$, are typically not of plant origin. However, ß-sitosterol, a principal plant sterol, can be converted into primary bile acids (Dayal et al. 1984). Bile acids are recognized as being involved in the regulation of a variety of mammalian metabolic processes (Houten, Watanabe, and Auwerx 2006), but their role in plant metabolism is less diverse. Treatment of certain plant tissues with a primary bile acid, such as cholic acid, has been shown to induce an accumulation of antimicrobial compounds as well as to elicit other plant defense mechanisms (Koga et al. 2006).

Figure 4. Representative mass spectra for compounds determined to be unique to $L$. cuneata exudate solutions. LC-ESI-MS spectra on the left and GC-MS spectra on the right.

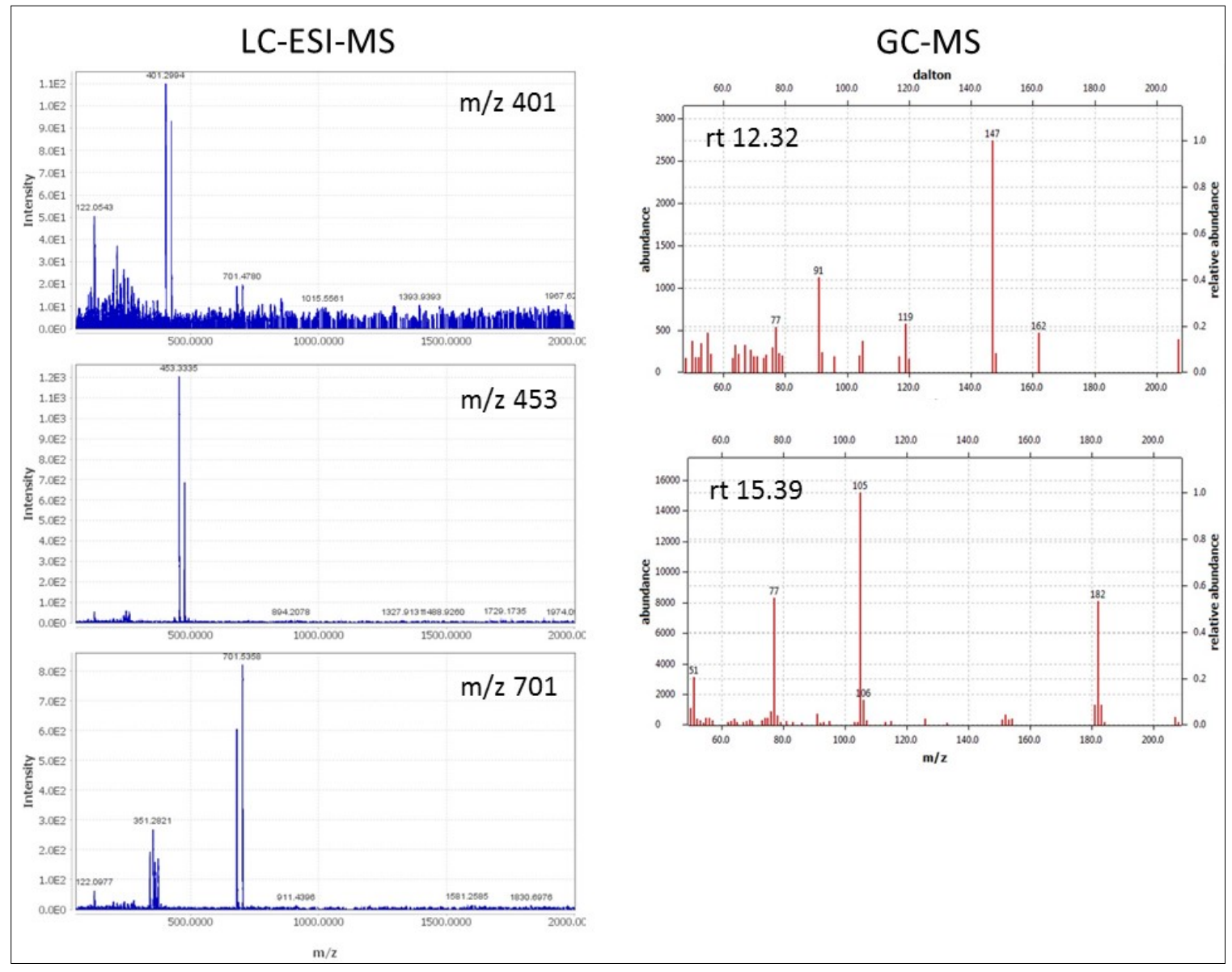


Table 3. Summary of METLIN search results against the base peak ions $(M+N a$ and $M+H)$ observed for the three unique peaks identified via LC-ESI-MS.

\begin{tabular}{|c|c|c|c|c|c|c|}
\hline rt & target $\mathrm{m} / \mathbf{2}$ & Tolerance (ppm) & $\mathrm{m} / \mathrm{z}$ & adduct & formula & possible name/structure \\
\hline \multirow[t]{12}{*}{12.37} & (475.3229) & 19 & 475.3394 & $\mathrm{M}+\mathrm{Na}$ & $\mathrm{C} 27 \mathrm{H} 4805$ & 5alpha-cholestan-3beta,6alpha,8beta,15alpha,24S-triol \\
\hline & $(453.3521)$ & 11 & 453.3575 & $\mathrm{M}+\mathrm{H}$ & & 5alpha-Cholestane-3beta,7alpha,12alpha,25,26-pentol \\
\hline & & & & & & $5 \beta$-Cholestane-3a,7a,12a,25,26-pentol \\
\hline & & & & & & alpha-Trichechol \\
\hline & & & & & & beta-T richechol \\
\hline & & & & & & omega-Trichechol \\
\hline & & & & & & Bufol \\
\hline & & & & & & Chimaerol \\
\hline & & & & & & Cholestane-3,7,12,24,25-pentol \\
\hline & & & & & & Cholestane-3alpha,7alpha,12alpha,24R,25-pentol \\
\hline & & & & & & Cyprinol \\
\hline & & & & & & Latimerol \\
\hline \multirow{2}{*}{14.83} & $(701.5012)$ & 9 & 701.5075 & $\mathrm{M}+\mathrm{Na}$ & C34H67010P & $P G(14 \cdot 0 / 14: 0)$ \\
\hline & $(679.5159)$ & 36 & 679.4908 & $\mathrm{M}+\mathrm{H}$ & $\mathrm{C} 36 \mathrm{H} 7109 \mathrm{P}$ & PG (P-16:0/14:0) \\
\hline \multirow[t]{6}{*}{14.97} & $(423.2846)$ & 5 & 423.287 & $\mathrm{M}+\mathrm{Na}$ & $\mathrm{C} 26 \mathrm{H} 4003$ & (17E)-1a,25-dihydroxy-17,20-didehydro-21-norvitamin D3 \\
\hline & $(401.2994)$ & 13 & 401.305 & $\mathrm{M}+\mathrm{H}$ & & 17 beta-Hydroxy-5alpha-androstan-3-one cyclohexanecarboxylate \\
\hline & & & & & & 19-Nor-14-epi-23-yne-1,25 dihydroxyvitamin D3 \\
\hline & & & & & & DHEAENANTH ATE \\
\hline & & & & & & Testosterone enanthate \\
\hline & & & & & & Ximaosteroid B \\
\hline & & & & & & \\
\hline
\end{tabular}

Analysis of the GC-MS data against the MassBank database also resulted in potential compound identifications. The compound eluting at a retention time of $15.30 \mathrm{~min}$ was matched to benzophenone $\left(\mathrm{C}_{13} \mathrm{H}_{10} \mathrm{O}\right)$, and the compound eluting at a retention time of $12.32 \mathrm{~min}$ corresponded to either diacetyl benzene $\left(\mathrm{C}_{10} \mathrm{H}_{10} \mathrm{O}_{2}\right)$ or methyl, 2,4,6-trimethylphenyl ketone $\left(\mathrm{C}_{11} \mathrm{H}_{14} \mathrm{O}\right)$. Potential structures are provided in Figure 5. Natural benzophenones have been isolated from fungi as well as higher plants, and they have been shown to exhibit a range of biological activities including antifungal, antimicrobial, antiviral, and cytotoxic activities (Wu, Long, and Kennelly 2014). Although diacetyl benzenes have been isolated from some plants (e.g., green tea), specific plant activities of these compounds are not fully understood.

Figure 5. Mass spectra and structures for two compounds detected in $L$. cuneata exudate solution by GC-MS.

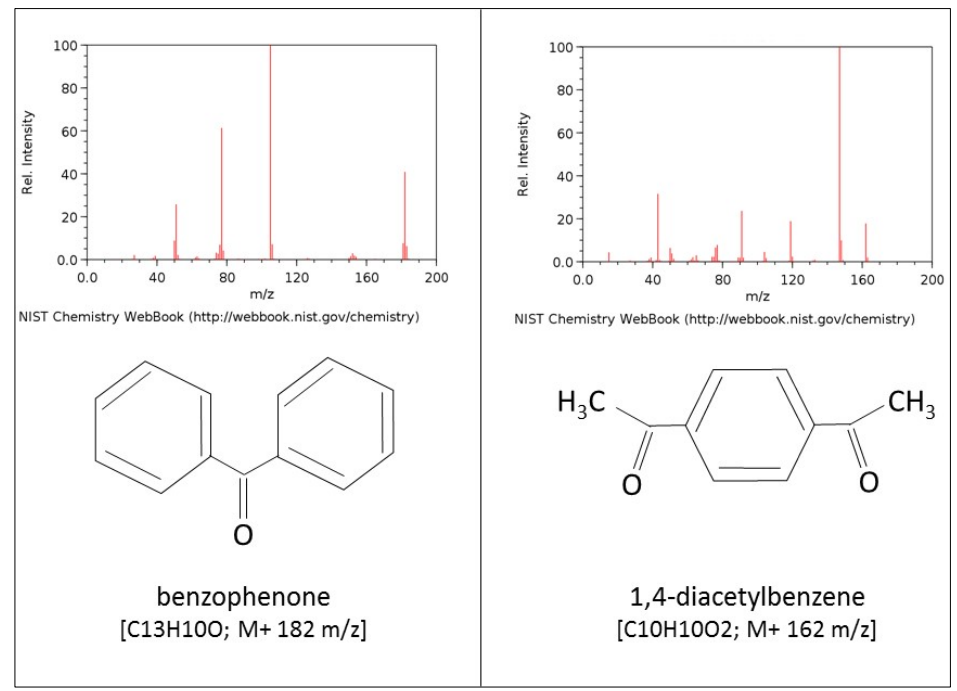


Discussion summary. Exudates from Lespedeza species were found to be chemically distinct from coexisting native prairie grasses. In particular, Lespedeza cuneata, and to a lesser extent a subset of $L$. virginica, could be differentiated based on the presence of five unique compounds. Two low molecular compounds were identified via GC-MS and tentatively identified as benzophenone and 1,4-diacetylbenzene. Additionally, three higher molecular weight compounds were identified by LC-ESI-MS, with possible relationships to 19-nor analogs of vitamin D, phosphatidylglycerol and primary bile acids or alcohols. As discussed, three of the compounds could be involved in plant defense mechanisms, either directly (e.g., benzophenone and phosphatidylglycerol) or indirectly as an elicitor (i.e., the putative bile acids). In addition, the putative vitamin $\mathrm{D}$ analogues have been shown to stimulate cell proliferation and differentiation and to effect calcium mobility, both of which are activities involved in plant defense mechanisms. Of additional interest is the identified anticancer (tumor suppressant) activities of 19-norvitamin analogs and natural benzophenones. Although these compounds were detected in both Lespedeza species, their prevalence and abundance was significantly greater in the invasive L. cuneata derived exudates.

This study was an initial step toward a better understanding of how Lespedeza cuneata and other invasive species obtain a competitive advantage, either by affecting how neighboring plants respond to exogenous compounds (e.g., elicit the release of defense mechanisms and impede associated cell signaling at a metabolic cost), or by imparting a competitive advantage through enhanced anti-pathogen and cell defenses. Additional research is needed to verify the molecular structure of the compounds identified in the plant exudates examined in this study and to elucidate their origin and modes of activity.

POINTS OF CONTACT: The POC for technical inquiries is David Ringelberg (David.B.Ringelberg@usace.army.mil). This technical note should be referenced as follows:

Ringelberg, David B., Alyssa M. Beck, Ryan R. Busby, Imee G. Smith, and Anthony C. Yannarell. 2017. Exudate Chemical Profiles Derived from Lespedeza and Other Tallgrass Prairie Plant Species. ERDC TN-17-1. Vicksburg, MS: U.S. Army Engineer Research and Development Center.

An electronic copy of this technical note is available from the ERDC library's digital repository: http://acwc.sdp.sirsi.net/client/default.

ACKNOWLEDGEMENTS: The use of trade, product, or firm names in this report is for descriptive purposes only and does not imply endorsement by the U.S. Government. The findings of this report are not to be construed as an official Department of the Army position unless so designated by other authorized documents. The tests described and the resulting data presented herein, unless otherwise noted, were obtained from research conducted under the Environmental Quality research program of the United States Army Corps of Engineers by the Engineer Research and Development Center.

\section{REFERENCES}

Badri, Dayakar V., Jacqueline M. Chaparro, Ruifu Zhang, Qirong Shen, and Jorge M. Vivanco. 2013. “Application of Natural Blends of Phytochemicals Derived from the Root Exudates of Arabidopsis to the Soil Reveals that Phenolic-Related Compounds Predominantly Modulate the Soil Microbiome." Journal of Biological Chemistry 288:4502-4512. 
Busby, Ryan R., Giselle Rodriguez, Dick L. Gebhart, and Anthony C. Yannarell. 2016. "Native Lespedeza Species Harbor Greater Non-Rhizobial Bacterial Diversity in Root Nodules Compared to the Coexisting Invader, $L$. cuneata." Plant and Soil 401:427-436.

Dayal, B., G. Salen, G.S. Tint, A.K. Batta, and S. Shefer. August 1984. "Synthesis of the Putative Metabolites of Plant Sterols: (24R)- and (24S)-24-methyl-5ß-cholestane-3 $\alpha, 7 \alpha, 12 \alpha, 25$-tetrols and 24-ethyl-5ß-cholestane$3 \alpha, 7 \alpha, 12 \alpha, 24 \Sigma$-tetro." Journal of Lipid Research 25(8):865-870.

Denight, Michael L., and Ryan R. Busby. 2007. U.S. Army Installation Floristic Inventory Database. Public Works Technical Bulletin \#200-1-52. Washington, DC: U.S. Army Corps of Engineers Headquarters, Civil Works. https://www.wbdg.org/ffc/army-coe/public-works-technical-bulletins-pwtb/pwtb-200-1-52.

Houten, Sander M., Mitsuhiro Watanabe, and Johan Auwerx. 2006. "Endocrine Function of Bile Acids." EMBO Journal 25(7):1419-1425. doi: 10.1038/sj.emboj.7601049.

Hu, Lingzi, Ryan R. Busby, Dick L. Gebhart, and Anthony C. Yannarell. 2014. "Invasive Lespedeza cuneata and Native Lespedeza virginica Experience Asymmetrical Benefits from Rhizobial Symbionts." Plant and Soil 384:315-325. doi: 10.1007/s11104-014-2213-7.

Kalburtji, K.L., and Jorge A. Mosjidis. 1993. "Effects of Sericea Lespedeza Root Exudates on Some Perennial Grasses." Journal of Range Management 46(4):312-315.

Koga, Jinichiro, Hidetoshi Kubota, Shuichi Gomi, Kenji Umemura, Masao Ohnishi, and Toshiaki Kono. 2006. "Cholic Acid, a Bile Acid Elicitor of Hypersensitive Cell Death, Pathogenesis-Related Protein Synthesis, and Phytoalexin Accumulation in Rice." Plant Physiology 140(4):1475-1483. doi: 10.1104/pp.105.070334.

Phillips, Richard P., Emily S. Bernhardt, and William H. Schlesinger. 2009. "Elevated $\mathrm{CO}_{2}$ Increases Root Exudation from Loblolly Pine (Pinus taeda) Seedlings as an N-mediated Response." Tree Physiology 29(12): 1513-1523. doi: 10.1093/treephys/tpp083.

Pimental, David, Rodolfo Zuniga, and Doug Morrison. 2007. Update on the environmental and economic costs associated with alien-invasive species in the United States. Ecological Economics 52(3):273-288.

Wada, Hajime, and Norio Murata. 2007. "The Essential Role of Phosphatidylglycerol in Photosynthesis." Photosynthesis Research 92(2):205-215. doi: 10.1007/s11120-007-9203-z.

Wu, Shi-Biao, Chunlin Long, and Edward J. Kennelly. 2014. "Structural Diversity and Bioactivities of Natural Benzophenones." Natural Product Reports 31(9):1158-74.

Yannarell, Anthony C., Ryan R. Busby, Michael L. Denight, Dick L. Gebhart, and Steven J. Taylor. 2011. "Soil Bacteria and Fungi Respond on Different Scales to Invasion by the Legume Lespedeza cuneata." Frontiers in Microbiology 2:127. doi 10.3389/fmicb.2011.00127.

Zhang, Xiaohui, Pengfei Li, Junying Bao, Santo V. Nicosia, Honggang Wang, Steven A. Enkemann, and Wenlong Bai. 2005. "Suppression of Death Receptor-Mediated Apoptosis by 1,25-dihydroxyvitamin D3 Revealed by Microarray Analysis." Journal of Biological Chemistry 280(42):35458-354685. 